\title{
Analisis Kepentingan Jerman dalam Pengiriman Main Battle Tank Leopard ke Indonesia (2012-2017)
}

\author{
Valery Ilhamna Putri \\ Pascasarjana Ilmu Hubungan Internasional, Fakultas Ilmu Sosial dan Ilmu Politik, \\ Universitas Indonesia - Indonesia \\ Email: valery.ilhamna@ui.ac.id
}

\begin{abstract}
This article is intended to analyze the reason behind the shipment of Main Battle Tank (MBT) Leopard by Germany to Indonesia from the year of 2012 until year 2017. Arms transfer is used with the purpose to increase wealth, power and to produce innovation in production of military power of a state. Arms transfer is an essential part from international security structure because it can influence a shift in local and regional power. This article argued that there are three power dimensions along with the intended influence in arms transfer pursued by supplier country. The intended power dimensions are bargaining power, structural power, and hegemonic power. At the end of the article, it is concluded that three power dimensions stated above complete and relate to each other to fulfill the supplier country's interest.
\end{abstract}

Keywords: Arms, Tank, Power, Influence, Indonesia, Germany

\begin{abstract}
Abstrak
Artikel ini berupaya untuk menganalisis alasan di balik pengiriman Main Battle Tank (MBT) Leopard milik Jerman ke Indonesia dari tahun 2012 hingga tahun 2017. Transfer senjata dilakukan dengan tujuan untuk menambah kekayaan, kekuatan dan menghasilkan inovasi dalam produksi kekuatan militer suatu negara. Transfer senjata merupakan bagian esensial dari struktur keamanan internasional karena dapat mempengaruhi pergeseran kekuatan lokal dan regional. Artikel ini berargumentasi adanya tiga dimensi kekuatan bersamaan dengan pengaruh yang dituju dalam melakukan transfer senjata oleh negara penyuplai. Dimensi-dimensi kekuatan yang dituju adalah kekuatan penawaran (bargaining power), kekuatan struktural (structural power), dan kekuatan hegemoni (begemonic power). Pada akhir artikel disimpulkan bahwa ketiga dimensi tersebut saling melengkapi dan berhubungan untuk mencapai kepentingan negara penyuplai persenjataan.
\end{abstract}

Kata Kunci: Senjata, Tank, Kekuatan, Pengaruh, Indonesia, Jerman 


\section{PENDAHULUAN}

Perdagangan

persenjataan merupakan aspek yang selalu dibahas dalam Hubungan Internasional. Transfer persenjataan telah dilakukan setidaknya sejak Peloponnesian Wars untuk mencapai tujuan politik, militer, dan ekonomi dari negara dan juga para pemimpin (Krause, 1992). Transfer persenjataan dan sistem produksi memiliki tiga fokus utama dalam Hubungan Internasional. Fokus-fokus tersebut adalah 'kekayaan' yang membentuk produksi dan distribusi barang didalam dan antar negara; 'kekuatan' atau power dimana negaranegara berupaya untuk mengubah posisinya dalam transfer dan sistem produksi senjata; dan 'perang' yang menghasilkan inovasi dalam produksi kekuatan militer (Krause, 1992).

Uni Eropa merupakan salah satu kawasan eksportir persenjataan tersbesar di dunia. Sejak awal tahun 1990an, kebijakan ekspor persenjataan Eropa telah melalui transformasi secara fundamental. Pengambilan keputusan tidak lagi terbatas pada level nasional, tetapi dilakukan melalui konsultasi, koordinasi dan harmonisasi secara multilateral. Proses ini memiliki efek terhadap kebijakan ekspor persenjataan nasional dan membentuk struktur yang diinstitusionalisasi bagi kerjasama kebijakan ekspor di Uni Eropa. Sehingga, pada akhirnya terbentuk kerangka kerja institusi
European Union's Common Foreign and Security Policy, yaitu European Union Code of Conduct for Arms Export atau Kode Etik Uni Eropa untuk Ekspor Persenjataan. Kode Etik tersebut disetujui pada tahun 1998 (Bauer, 2003).

Kode etik tersebut dibentuk agar adanya kontrol terhadap ekspor persenjataan negara-negara Uni Eropa. Kontrol tersebut terkait penolakan pemberian lisensi ekspor senjata jika ekspor senjata akan memprovokasi atau memperpanjang konflik persenjataan atau ketegangan di negara tujuan akhir. Serta, penolakan lisensi juga akan diberlakukan jika adanya resiko bahwa ekspor persenjataan tersebut akan digunakan secara agresif melawan negara lainnya atau melakukan klaim teritori (Bauer, 2003).

Produsen persenjataan Eropa memiliki peran yang penting dalam pasar persenjataan global. Lima eksportir persenjataan Eropa terbesar yaitu Perancis, Jerman, Italia, Spanyol dan Inggris memiliki kontribusi sebanyak $21 \%$ di perdagangan persenjataan dunia antara tahun 2011 hingga 2015 (Heiduk, 2017). Hampir seluruh negara-negara di Eropa yang memproduksi persenjataan utama merupakan penyuplai persenjataan di negara-negara Asia Tenggara. Pemerintah dan perusahaan di negaranegara Uni Eropa beranggapan bahwa Asia Tenggara merupakan pasar yang 
menjanjikan. Perusahaan-perusahaan persenjataan Eropa memiliki peran yang besar dalam peningkatan persenjataan di Asia Tenggara (Wezeman, 2019).

Jerman merupakan salah satu negara yang memiliki peran penting dalam perekonomian dan merupakan salah satu eksportir persenjataan terbesar baik di Uni Eropa maupun di dunia. Salah satu negara di Asia Tenggara yang memiliki kerjasama dengan Jerman adalah Indonesia. Indonesia memiliki hubungan diplomatik dengan Jerman yang diawali sejak tahun 1952 (Kementerian Luar Negeri Indonesia, t.t). Dalam bidang pertahanan, Indonesia dan Jerman menetapkan penandatanganan Nota Kesepahaman atau Memorandum of Understanding (MOU) mengenai Kerja Sama di Bidang Pertahanan pada tanggal 27 Februari 2012 di Berlin (Kementerian Luar Negeri Indonesia, t.t). Lalu Pada tanggal 8 November 2012, adanya penandatanganan nota kesepahaman terkait pengadaan Main Battle Tank (MBT) Leopard di Jakarta (Kementerian Pertahanan Republik Indonesia, 2012).

Tetapi, pengadaan MBT Leopard tersebut mengundang berbagai perdebatan. Hal tersebut dikarenakan Indonesia dianggap memiliki catatan sebagai negara yang pernah melakukan pelanggaran Hak Asasi Manusia (HAM). Serta, adanya protes dari aktivis HAM Jerman yang menampung suara dari sejumlah anggota parlemen yang keberatan terkait rencana pemerintah Jerman dalam penjualan MBT Leopard ke Indonesia. Protes tersebut muncul akibat adanya kekhawatiran Indonesia akan melakukan kembali pelanggaran HAM jika dikirimkan MBT Leopard (Pratomo, 2012). Sebelumnya, Indonesia sempat mencoba untuk membeli MBT Leopard milik Belanda yang pada akhirnya ditolak karena adanya alasan terkait pelanggaran HAM di Indonesia (Tempo, 2012). Jerman dan Belanda merupakan negara-negara anggota Uni Eropa yang memiliki regulasi ketat terkait ekspor persenjataan. Tetapi, pada akhirnya pemerintah Jerman tetap setuju untuk mengirimkan MBT Leopard ke Indonesia. Artikel ini berargumentasi bahwa adanya kekuatan dan pengaruh yang dituju oleh Jerman sebagai negara penyuplai persenjataan ke Indonesia sebagai negara penerima persenjataan. Kekuatan yang dituju diantaranya adalah bargaining power, structural power dan hegemonic power.

\section{TINJAUAN LITERATUR}

Telah banyak penelitian yang membahas mengenai transfer senjata Jerman, yang merupakan salah satu negara dengan kekuatan militer terbesar di Uni Eropa. Penelitianpenelitian yang telah dilakukan 
sebelumnya dapat dikategorikan menjadi empat kategori, yaitu

Ekonomi-Politik; (2) Kajian Kawasan; (3) Isu pertahanan domestic; dan (4) Argumentative Papers. Kategori yang pertama yaitu ekonomi-politik yang menjelaskan bahwa Jerman dalam praktik ekspor senjata berorientasi sebagai trading state, karena adanya industri persenjataan yang berorientasi ekspor dan adanya kontribusi pada ekspansi sistem militer global, serta adanya dukungan pemerintah Jerman yang dapat meningkatkan pengaruh Jerman di negara lain (Plate \& Leuffen, 2016; Wulf, 1998; Epkenhans, 2003).

Kategorisasi kedua, yaitu kajian kawasan yang menjelaskan Kebijakan persenjataan Jerman dikarakterisasikan oleh kepentingan kawasan dan kerjasama persenjataan merupakan hal yang esensial untuk memperkuat pertahanan kawasan Uni Eropa (Rohde \& Schmidt, 1995; Sudreau, 2019). Kategorisasi ketiga yaitu isu pertahanan domestik, kebijakan transfer senjata Jerman dipengaruhi faktor ekonomi dan militer. Secara ekonomi, Jerman memikul beban karena unifikasi, unifikasi tersebut memiliki efek pada kebijakan pertahanan yaitu adanya restrukturisasi dan mengakibatkan adanya surplus senjata yang menjadikan ekspor sebagai cara utama untuk mengurangi surplus persenjataan (Ericson, 2013; Kenny \& Stessen, 2013; Beeck, 2008).
Lalu, kategorisasi keempat dijelaskan melalui argumentative papers, yang menjelaskan bahwa perusahaan transnasional Jerman mengontrol produksi pertahanan agar industri persenjataan Jerman tetap mandiri, sehingga dibutuhkannya kebijakan ekspor persenjataan yang aktif (Lock \& Voß, 1994; Albrecht, 1986).

Sebagaimana telah disebutkan didalam penelitian-penelitian terdahulu, ekspor senjata yang telah dilakukan Jerman mengarah kepada kepentingan ekonomi, kajian kawasan terkait kebijakan ekspor senjata di Uni Eropa, isu pertahanan domestik Jerman, serta dijelaskan juga melalui argumentative papers terkait industri pertahanan Jerman yang mengedepankan ekspor persenjataan. Dari literatur-literatur yang telah ada, dapat dilihat bahwa masih minimnya pendekatan literatur terkait transfer senjata yang menggunakan kerangka kerja konseptual dalam menganalisa pola dan variasi dari kebijakan transfer senjata ke negara lain. Serta, masih minimnya literatur terkait transfer senjata Jerman ke negara lain yang dibahas secara spesifik.

Hal tersebut menjadi suatu fakta yang menarik. Karena, belum ada penelitian yang berfokus pada pengiriman MBT Leopard ke Indonesia oleh Jerman yang mengkaji secara lebih dalam terkait kepentingan Jerman dalam pengiriman MBT 
Leopard ke Indonesia. Sehingga adanya celah untuk melakukan penelitian lebih lanjut tentang analisis kepentingan Jerman dalam melakukan ekspor MBT Leopard ke Indonesia dengan rentang waktu dari tahun penandatanganan nota kesepahaman pada tahun 2012 hingga tahun penyelesaian pengiriman tank Leopard pada tahun 2017.

\section{KERANGKA ANALISIS}

Penelitian ini akan menggunakan konsep kekuatan dan pengaruh dalam hubungan transfer senjata milik Keith Krause. Tulisan Krause berfokus pada penggunaan kekuatan militer, yaitu terkait hubungan transfer persenjataan sebagai alat untuk menyebarkan pengaruh suatu negara. Argumentasi yang diberikan adalah bahwa masih kurangnya analisis tentang transfer persenjataan secara konseptual terkait penggunaan pengaruh atau influence antara negara dengan kekuatan yang kuat dan lemah. Konsep ini berangkat dari paradigma realisme yang berfokus pada perilaku aktor negara (Krause, 1991).

Penelitian mengenai transfer senjata merupakan hal yang penting, karena hubungan transfer senjata dengan bantuan militer merupakan salah satu alat terpenting dalam penggunaan kekuatan militer untuk kenegaraan. Analisis mengenai transfer senjata juga dijelaskan oleh beberapa pemikir, diantaranya adalah John Sislin, David Kinsella, Barry Buzan, Ole Waever, dan Paul W. Thurner. Sislin menejelaskan bahwa adanya manipulasi melalui ekspor persenjataan untuk membuat negara penerima mengikuti keinginan dari negara penyuplai (Sislin, 1994). Argumentasi tersebut diperkuat oleh penjelasan bahwa dalam transfer senjata adanya dimensi militer dan politik, serta juga adanya implikasi pada perilaku negara. Transfer senjata memperlihatkan hubungan antara negara penyuplai dan negara penerima, serta hubungan tersebut memiliki signifikansi politik yang berbeda. Beberapa mengharuskan negara penerima agar bertransaksi di pasar internasional tertentu. Beberapa lainnya berkomitmen pada keamanan nasional negara penerima, dan kemungkinan memiliki implikasi pada stabilitas kawasan (Kinsella, 1998). Transaksi persenjataan merupakan bagian penting dari struktur keamanan internasional karena memiliki potensi mempengaruhi pergeseran kekuatan secara lokal dan regional (Buzan \& Waever, 2003; Thurner, 2019). Penjelasan-penjelasan tersebut memperkuat argumentasi Krause tentang pengaruh dan kekuatan dalam transfer senjata.

Krause menjelaskan adanya tiga dimensi kekuatan dan pengaruh yang dituju oleh negara penyuplai, yaitu 
Bargaining Power, Structural Power, dan Hegemonic Power. Bargaining power yaitu adanya pemenuhan atau kepatuhan negara penerima terhadap keinginan atau permintaan tertentu dari negara penyuplai; Structural power berupaya untuk mencapai tujuan yang lebih umum/general yang memfasilitasi pencapaian tujuan tertentu; Hegemonic power berupaya untuk mendapatkan tujuan tertentu tanpa penggunaan kekuatan atau penyebaran pengaruh yang terlihat secara langsung. Krause menjelaskan bahwa ketiga dimensi tersebut saling mempengaruhi.

Dimensi pertama adalah bargaining power, bargaining power memiliki efek langsung atau jangka pendek, sehingga adanya pengaruh terhadap isu spesifik yang menjadi perhatian negara penyuplai. Dilakukan dengan memanipulasi transfer senjata melalui ancaman hukuman atau dengan janji untuk memberikan hadiah atau rewards sebagai cara langsung untuk mendapatkan tujuan yang spesifik. Semakin besar kapabilitas yang dimiliki oleh suatu negara untuk memberikan hadiah atas kepatuhan atau menghukum negara yang tidak bersedia untuk bekerjasama, maka negara tersebut memiliki kekuatan dan kemampuan untuk mempengaruhi yang lebih besar (Neuman, 2009). Dimensi kedua adalah structural power yang memiliki efek jangka menengah. Dalam hubungan pertahanan dan keamanan negara, negara penyuplai dapat mengaplikasikan dua pengaruh struktural pada negara penerima. Negara penyuplai dapat merubah ancaman yang dihadapi oleh negara penerima, yaitu melalui transfer senjata, atau negara penyuplai dapat membatasi dan memperluas respon negara penerima terkait ancaman yang dihadapi.

Structural power dilakukan ketika negara penyuplai merubah pilihan yang tersedia untuk negara penerima, atau membuat perubahan pilihan menjadi lebih murah ataupun lebih mahal bagi negara penerima. Manipulasi tersebut tidak selalu terlihat oleh negara penerima, tetapi dapat terlihat seiring berjalannya waktu. Dalam hubungan transfer senjata, kekuatan struktural dapat dilakukan dengan menyediakan atau menahan jenis dan jumlah senjata yang memfasilitasi atau membatasi strategi militer tertentu (seperti kapabilitas counter-value). Dalam melihat aplikasi kekuatan struktural, karena penekanan pada tujuan yang lebih umum dan dengan jangka waktu lama, maka tidak adanya tuntutan akan konflik.

Dimensi ketiga adalah hegemonic power yang memiliki efek jangka panjang. Hegemonic power terkait pengaruh pada konsep yang menguasai bidang militer dan kebijakan keamanan, seperti nature of the threat / sifat ancaman yang dihadapi oleh suatu 
negara, pemahaman tentang bagaimana cara untuk mendapatkan keamanan, dan definisi tentang keamanan sendiri. Hegemonic power digunakan dengan mempengaruhi elit pembuat kebijakan dan melegitimasi pemahaman tertentu terkait keamanan agar sepemahaman dengan negara penyuplai. Hegemonic power berfokus pada kepentingan global dan konfrontasi negara-negara besar/super power. Jika melihat upaya mencapai hegemonic power, dapat dilihat dengan ilustrasi bagaimana kontak dengan negara penyuplai melalui transfer senjata/bantuan militer dapat turut membentuk perilaku aktor-aktor utama dan juga kepercayaan pada isuisu keamanan serta memperlihatkan bagaimana hal tersebut memberikan hasil yang menguntungkan bagi negara penyuplai.

Konsep tentang pengaruh dan kekuatan yang dijelaskan oleh Krause akan digunakan untuk menjelaskan penelitian ini. Ketiga dimensi kekuatan yaitu bargaining power, structural power, dan begemonic power yang saling melengkapi akan digunakan untuk menganalisis tujuan Jerman dalam melakukan transfer senjata Main Battle Tank (MBT) Leopard ke Indonesia yang dilakukan secara bertahap dari tahun 2012 hingga tahun 2017.
ANALISIS DAN PEMBAHASAN

Dalam menganalisis kepentingan Jerman melakukan pengiriman Main Battle Tank (MBT) Leopard ke Indonesia, adanya dimensi kekuatan (power) dan pengaruh (influence) yang dituju oleh negara penyuplai persenjataan dalam melakukan pengiriman senjata ke negara penerima. Jerman dalam mengirimkan MBT Leopardnya memiliki kepentingan untuk mengaplikasikan pengaruhnya terhadap Indonesia dan akan dijelaskan melalui aplikasi tiga dimensi kekuatan untuk menjelaskan posisi Jerman sebagai bargaining power, structural power dan hegemonic power.

\section{Bargaining Power Jerman Sebagai Negara Penyuplai Tank Leopard}

Bargaining power merupakan dimensi kekuatan yang memiliki efek langsung atau jangka pendek, sehingga adanya pengaruh terhadap isu spesifik yang menjadi perhatian negara penyuplai. Bargaining power dilakukan dengan memanipulasi transfer senjata melalui ancaman hukuman atau dengan janji pemberian hadiah atau rewards sebagai cara langsung untuk mendapatkan suatu tujuan yang spesifik.

Jerman merupakan negara dengan jumlah ekspor persenjataan terbesar ke-5 di dunia (SIPRI, t.t). Jerman memiliki kapabilitas militer yang cukup tinggi, dapat dilihat dari 
peringkat kekuatan militer Jerman yang menempati peringkat ke 13 di dunia (globalfirepower, t.t). Selain itu, Jerman juga merupakan salah satu negara dengan perekonomian terkuat di Uni Eropa. Karena hal tersebut, Jerman memiliki pengaruh yang cukup besar baik di Uni Eropa dan di dunia. Jerman, bersama dengan negara Uni Eropa lainnya memiliki kontrol terkait ekspor persenjataan yang cukup ketat, yaitu European Union's Common Foreign and Security Policy, yaitu European Union Code of Conduct for Arms Export atau kode etik pada ekspor persenjataan (Bauer, 2003). Kode etik tersebut dibentuk untuk menghindari konflik atau penggunaan senjata secara agresif oleh negara yang dituju.

Indonesia, merupakan negara yang pernah memiliki catatan pelanggaran HAM berupaya untuk mendapatkan Main Battle Tank (MBT) Leopard milik Jerman. Pemerintah Indonesia telah mengungkapkan secara rinci terkait rencana pembelian MBT Leopard. Tetapi, Jerman pada awalnya menolak untuk memberikan keterangan resmi terkait persetujuan penjualan MBT tersebut. Rencana penjualan MBT Leopard oleh Jerman dikritik berbagai organisasi HAM di Jerman (Deutsche Welle, 2013).

Organisasi tersebut menilai bahwa situasi hak asasi di beberapa daerah di Indonesia masih sangat buruk. Sebagian anggota parlemen di
Jerman juga menolak rencana penjualan tank tersebut ke Indonesia. Partai Hijau dan Partai Kiri menyatakan kekhawatirannya bahwa Indonesia akan menggunakan senjata yang dibeli dari Jerman untuk menghadapi aksi protes dan kelompok etnis minoritas. Kanselir Angela Merkel dalam kunjungan ke Indonesia pada pertengahan tahun 2012 sempat membahas kerjasama militer dengan Indonesia. Tetapi, dalam pembahasan tersebut tidak disebutkan secara konkret terkait rencana penjualan senjata (Deutsche Welle, 2013).

Jerman merupakan negara yang menjunjung tinggi HAM. Hal tersebut dapat dilihat dari kebijakan luar negeri Jerman yang mempromosikan penguatan demokrasi, supremasi hukum, dan HAM di seluruh dunia. Dukungan Jerman terhadap prinsipprinsip tersebut termasuk dalam kepentingan kebijakan luar negeri Jerman. Kedamaian, keamanan, stabilitas, serta pembangunan yang berkelanjutan hanya dapat berlangsung dalam waktu yang lama dimana prinsip-prinsip demokrasi dan supremasi hukum diaplikasikan dan adanya respek terhadap HAM. Karena itu, Jerman secara percaya diri mempromosikan demokrasi, supremasi hukum dan HAM sebagai salah satu komponen penting dalam kebijakan perdamaian dan keamanan 
Jerman (Federal Foreign Office Germany, t.t).

Dalam rencana pembelian tank Leopard, pihak Indonesia yang diwakili oleh Komisi I Dewan Perwakilan Rakyat Republik Indonesia (DPR RI) mengunjungi Jerman di tahun 2012. Pihak Indonesia menemui Ketua Komisi Pertahanan Parlemen Jerman, Hon. Mrs. Susanne Kastner, MdB pada tanggal 24 April 2012 (Dewan Perwakilan Rakyat Indonesia, 2012). Pada saat itu, dijelaskan bahwa Indonesia sedang berupaya untuk melakukan peremajaan alat utama sistem senjata (alutsista) Indonesia. Peremajaan yang dilakukan bukanlah untuk menciptakan instabilitas dalam negeri maupun di kawasan. Tetapi, tujuan peremajaan tersebut adalah untuk meningkatkan kapabilitas pertahanan Indonesia dalam menjaga kedaulatan dan keutuhan wilayahnya (Dewan Perwakilan Rakyat Indonesia, 2012).

Delegasi Komisi I DPR RI juga meminta dukungan terhadap rencana peremajaan alutsista Indonesia pada pertemuan dengan Parliamentary State Secretary Kementerian Ekonomi dan Teknologi Republik Federal Jerman, Hon. Mr. Hans-Joachim Otto pada tanggal 25 April 2012 (Dewan Perwakilan Rakyat Indonesia, 2012). Karena, kementerian tersebut merupakan lembaga yang paling menentukan dalam pemberian lisensi ekspor persenjataan di Jerman. Mr. Otto menjelaskan bahwa Jerman memandang Indonesia sebagai negara yang stabil dan demokratis. Indonesia juga dianggap sebagai stabilisator kawasan dan penting sebagai mitra Jerman dalam kerja sama ekonomi (Dewan Perwakilan Rakyat Indonesia, 2012).

Indonesia, melalui Presiden Susilo Bambang Yudhoyono pada saat Deklarasi Jakarta juga memperkuat tujuan penggunaan MBT Leopard. MBT Leopard tersebut tidak akan digunakan untuk melawan rakyat Indonesia (Waluyo, 2012). Presiden Yudhoyono memastikan bahwa semua penggunaan persenjataan bersifat transparan, terbuka dan tidak berniat untuk disalahgunakan. Indonesia tidak pernah menggunakan persenjataannya untuk melukai rakyat. Persenjataan tersebut digunakan sebagai alat untuk mempertahankan kedaulatan. Tank tersebut akan digunakan untuk meningkatkan postur pertahanan Indonesia dan untuk modernisasi alat utama sistem persenjataan (alutsista) Indonesia yang sudah usang.

Kemudian, Indonesia dengan Jerman melalui PT. Pindad dan Rheinmetall milik Jerman pada bulan November 2012 menandatangani nota kesepahaman terkait pengadaan Main Battle Tank (MBT) Leopard di Jakarta. Penandatanganan tersebut dilakukan di acara pameran Alutsista Indo Defence 
2012 di Jakarta International Expo Kemayoran, Jakarta Utara (Kementerian Pertahanan Republik Indonesia, 2012). Selain penandatanganan nota kesepahaman pengadaan tank Leopard tersebut, juga ditandatangani nota serupa terkait alih teknologi (Transfer of Technology / ToT). Alih teknologi pengadaan MBT Leopard akan diberikan kepada PT. Pindad, Bengkel Pusat Peralatan (Bengpuspal) Direktorat Peralatan Angkatan Darat (Ditpalad), serta Bengkel Pusat Perhubungan (Bengpushub) Direktorat Perhubungan Angkatan Darat (Dithubad).

Dapat dilihat bahwa Jerman menggunakan kekuatan bargaining untuk mendapatkan tujuan tertentu, yaitu memastikan bahwa Indonesia tidak akan menggunakan MBT Leopard untuk melakukan pelanggaran HAM. Hal tersebut dilakukan melalui pertemuan pihak Indonesia melalui Komisi I DPR RI dengan pihak Jerman mengenai tujuan pembelian MBT Leopard, serta pernyataan yang disampaikan langsung oleh Presiden Indonesia yaitu Susilo Bambang Yudhoyono. Bargaining power memiliki efek langsung atau dalam jangka pendek. Jerman, sebagai negara yang memiliki kapabilitas militer yang besar, menggunakan kekuatan bargaining nya agar Indonesia mengikuti keinginan Jerman dengan memberikan janji atas hadiah / rewards dimana rewards diberikan dalam bentuk pengiriman MBT Leopard. Rewards tersebut juga dilengkapi oleh alih teknologi MBT Leopard ke Indonesia (Kementerian Pertahanan Republik Indonesia, 2012). Hal tersebut memperlihatkan bahwa Jerman, sebagai negara penyuplai memiliki kekuatan dan kemampuan untuk mempengaruhi negara penerima, yaitu Indonesia. Indonesia berhasil meyakinkan Jerman bahwa Indonesia merupakan negara yang stabil dan MBT Leopard tidak akan disalahgunakan untuk memicu konflik atau untuk tujuan agresi sesuai dengan kebijakan Jerman terkait ekspor persenjataan.

\section{Structural Power Jerman Sebagai Penyuplai Tank Leopard}

Structural power merupakan dimensi kekuatan yang memiliki efek jangka menengah. Dalam hubungan pertahanan dan keamanan negara, negara penyuplai dapat mengaplikasikan dua pengaruh struktural pada negara penerima. Negara penyuplai dapat merubah ancaman yang dihadapi oleh negara penerima, yaitu melalui transfer senjata atau negara penyuplai dapat membatasi dan memperluas respon negara penerima terkait ancaman yang dihadapi. 
Dalam hubungan transfer senjata, kekuatan struktural dapat dilakukan dengan menyediakan atau menahan jenis dan jumlah senjata yang memfasilitasi atau membatasi strategi militer. Dalam melihat aplikasi kekuatan struktural, karena penekanan pada tujuan yang lebih umum dan dengan jangka waktu cukup lama, maka tidak adanya tuntutan akan konflik.

Pada awalnya, Indonesia berencana untuk membeli Main Battle Tank (MBT) Leopard dari Belanda sebanyak 119 tank (Patnistik, 2012). Tetapi, dalam rencana tersebut adanya keberatan serta kendala politik baik di Indonesia dan di Belanda. Pihak Indonesia, yaitu dari Dewan Perwakilan Rakyat (DPR) awalnya meragukan terkait manfaat tank Leopard di Indonesia, karena Indonesia merupakan negara kepulauan. Kendala kedua adalah alasan Belanda untuk menjual MBT Leopard tersebut ke Indonesia sebagai negara yang pernah tercatat melanggar HAM. Dalam internal kabinet Belanda terbagi dalam dua pendapat. Menteri Pertahanan Belanda Hans Hillen memperlihatkan jiwa dagang Belanda, tetapi pada saat yang bersamaan Belanda juga mementingkan permasalahan terkait moral.

Parlemen Belanda tidak menyetujui rencana Pemerintah Belanda untuk menjual tank Leopard tersebut ke Indonesia. Alasan yang dikemukakan adalah karena tentara Indonesia pernah melakukan pelanggaran HAM di Aceh, Timor Timur, dan Papua Barat. Tetapi, alasan tersebut dinilai kurang kuat oleh Menteri Luar Negeri Belanda Uri Rosenthal karena pelanggaran tersebut terjadi di masa lalu. Tetapi, kemudian adanya argumen pada masa sekarang masih adanya pelanggaran HAM di Maluku dan Papua, serta mempertimbangkan posisi kaum minoritas Indonesia. Karena itu, Belanda pada akhirnya menolak untuk menjual tank Leopard ke Indonesia karena dikhawatirkan Indonesia akan kembali melakukan pelanggaran HAM.

Karena ada penolakan oleh Parlemen Belanda untuk menjual MBT Leopard, Indonesia kemudian harus beralih dari pasar Belanda. Kemudian, Indonesia berupaya untuk mendapatkan MBT Leopard dari Jerman. Jerman yang awalnya tidak memberikan kejelasan akan menjual tank tersebut ke Indonesia, pada akhirnya menyetujui untuk melakukan penjualan MBT Leopard. Dapat dilihat bahwa Jerman awalnya menggunakan bargaining power untuk mendapatkan tujuan spesifik, yaitu Indonesia tidak akan menggunakan MBT Leopard tersebut untuk menyerang masyarakatnya. Dimensi kekuatan dan pengaruh yang digunakan Jerman tidak 
hanya bargaining power, tetapi juga structural power.

Jerman kemudian menyetujui kesepakatan oleh perusahaan pertahanan Rheinmetall untuk ekspor 103 tank Leopard 2A4 ke Indonesia. Sebagai tambahan, sebanyak 42 kendaraan tempur infanteri Marder 1A3 akan dikirim juga sebagai bagian dari kesepakatan, serta 11 kendaraan militer lainnya termasuk kendaraan lapis baja dan kendaraan teknik (Hardy, 2013).

Pembelian tank Leopard oleh Indonesia bernilai sebesar 280 juta USD, tank tersebut kemudian dimodifikasi dengan menambahkan pendingin ruangan. Tank Leopard 2A4 memiliki berat 63 ton, panjang 9,97 meter, lebar 3,75 meter dan tinggi 3 meter. Tank tersebut juga memiliki mesin V-12 twin turbo diesel dengan kekuatan 1.400 daya kuda. Dengan tangki solar berisi 1.200 liter, tank Leopard dapat menempuh radius 550 kilometer dengan kecepatan maksimum 70 kilometer/jam. Tank Leopard juga dilengkapi oleh meriam smoothbore kaliber 120 milimeter. Meriam tersebut menjadikan Leopard sebagai tank terbesar yang pernah dimiliki oleh Indonesia. Tentara Nasional Indonesia (TNI) sebelumnya hanya memiliki tank ringan AMX-13 dan Scorpion, dengan meriam kaliber 75-90 milimeter (Tempo, 2014). Keberadaan tank Leopard dibutuhkan untuk efek gentar (deterrence) terhadap potensi ancaman dari luar Indonesia. Indonesia juga membutuhkan Main Battle Tank karena sebelumnya hanya memiliki light dan medium battle tank, sedangkan negara-negara di Asia Tenggara rata-rata sudah memiliki Main Battle Tank (Sihite, 2014).

Selain itu, PT. Pindad dan Rheinmetall milik Jerman menandatangani nota kesepahaman pada tanggal 7 Agustus 2014 di Hotel Shangrila, Jakarta. Penandatanganan nota kesepahaman tersebut bertujuan untuk menetapkan kerangka kerjasama antara PT. Pindad dengan Rheinmetall dalam mengembangkan bisnis jangka panjang dalam bidang amunisi di Indonesia. Beberapa poin yang dibahas diantaranya mengenai kerjasama dalam bidang amunisi dengan berbagai kaliber sesuai kebutuhan PT. Pindad bagi kebutuhan TNI disesuaikan dengan kondisi yang ada, membangun co-manufacturing amunisi di fasilitas produksi PT. Pindad, pengalihan pemanfataan teknologi terkait amunisi, dan potensi PT Pindad sebagai bub manufacturing atau pusat manufaktur di kawasan Asia Pasifik. Kerjasama tersebut dapat mendorong pemenuhan produk alutsista secara lebih maksimal dengan kualitas yang lebih baik. PT. Pindad sebagai bub manufacturing di kawasan Asia Pasifik dapat meningkatkan daya saing PT. Pindad di kawasan. 
Rheinmetall sepakat untuk membangun akademi atau lembaga pelatihan dalam rangka peningkatan kualitas Sumber Daya Manusia (SDM) dari PT. Pindad (PT. Pindad, 2014).

Dapat dilihat bahwa Jerman menggunakan pengaruhnya dalam mengaplikasikan structural power. Jerman dapat membatasi respon pada ancaman yang dihadapi oleh Indonesia melalui transfer senjata. Yaitu, terkait ancaman pada kedaulatan yang dihadapi oleh Indonesia. Hal tersebut dikarenakan negara-negara di Asia Tenggara telah memiliki tank tempur utama (main battle tank).

Untuk menjaga kedaulatan Indonesia, Indonesia membutuhkan tank tempur utama. Pengadaan tank Leopard bertujuan untuk modernisasi alutsista milik TNI-AD. Hal tersebut dilakukan karena sistem persenjataan Indonesia telah tertinggal dari negaranegara lain di Asia Tenggara. Keberadaan alutsista dalam pertahanan modern merupakan hal utama untuk mempertahankan kedaulatan wilayah negara (Rachmat, 2014).

Jerman dapat merubah pilihan yang tersedia bagi Indonesia, Tank Leopard dinilai sebagai tank berat terbaik di kelasnya di Asia Tenggara dan termasuk dalam kelompok tank tempur utama terbaik dunia (Sitanggang, 2014). Sehingga
Indonesia pada akhirnya tetap memilih Jerman untuk melakukan pembelian Main Battle Tank (MBT) Leopard. Hal tersebut terlihat dari kekuatan penggentar Leopard yang dibutuhkan, dan adanya modifikasi MBT Leopard sesuai dengan kondisi wilayah Indonesia. Efek dari structural power memiliki jangka waktu menengah, dan efeknya tidak langsung terlihat. Tetapi, efek dari penggunaan structural power dapat dilihat dari awal penandatanganan nota kesepahaman antara Indonesia dengan Jerman pada tahun 2012 untuk pengadaan MBT Leopard di Indonesia, kemudian adanya nota kesepahaman kembali melalui PT. Pindad dan Rheinmetall pada tahun 2014 yang menjadikan PT. Pindad sebagai pusat manufaktur Rheinmetall di kawasan Asia Pasifik.

\section{Hegemonic Power Jerman Sebagai Negara Penyuplai Tank Leopard}

Dimensi ketiga adalah hegemonic power yang memiliki efek jangka panjang. Hegemonic power digunakan dengan mempengaruhi elit pembuat kebijakan dan melegitimasi pemahaman tertentu terkait keamanan agar memiliki pemahaman yang sama dengan negara penyuplai. Penggunaan Hegemonic power dapat dilihat melalui ilustrasi bagaimana kontak dengan negara penyuplai melalui transfer senjata. Serta, bantuan militer juga turut membentuk perilaku aktor-aktor 
utama dan juga kepercayaan pada isuisu keamanan dan memperlihatkan bagaimana hal tersebut memberikan hasil yang menguntungkan bagi negara penyuplai.

Hegemonic power berupaya untuk mendapatkan tujuan tertentu tanpa penggunaan kekuatan yang terlihat secara langsung dan memiliki efek jangka panjang. Dalam aplikasi hegemonic power yang digunakan oleh Jerman, dapat dilihat bahwa Jerman telah menggunakan dimensi bargaining power dan structural power. Upaya kerjasama pertahanan dengan Indonesia memiliki beberapa keuntungan untuk Jerman, karena kerjasama tersebut dapat memperluas hubungan di sektor lainnya. Selain kerjasama yang dilakukan memberikan keuntungan bagi Indonesia yang membutuhkan persenjataan baru serta adanya transfer teknologi terkait pengiriman MBT Leopard, kerjasama yang dilakukan juga dapat mendukung keikutsertaan Jerman dalam permasalahan Laut China Selatan. Meskipun tidak terlibat secara langsung pada permasalahan di Laut China Selatan, Jerman memiliki kepentingan dalam wilayah sengketa tersebut.

Dalam permasalahan Laut China Selatan, Uni Eropa menganggap bahwa kebebasan navigasi merupakan hal utama bagi Eropa, bahkan di Laut China Selatan (Hayton, 2019). Jerman, melalui Angela Markel pada kunjungan ke China di tahun 2015 mengatakan bahwa rute perdagangan laut merupakan hal yang esensial, maka dari itu rute tersebut harus tetap bebas dan aman, karena Laut China Selatan sangat penting bagi semua (The guardian, 2015).

Negara-negara Asia Tenggara memiliki persepsi ancaman yang sama terhadap China. Dapat dilihat dari upaya modernisasi kapabilitas militer tiap negara di Asia Tenggara. Hal tersebut diakibatkan oleh adanya kekhawatiran pada masa depan kawasan Asia-Pasifik karena kebangkitan China dan berkurangnya pengaruh Amerika di kawasan (Prajuli, 2013). Indonesia merupakan salah satu negara yang khawatir akan peningkatan sikap agresif China di Laut China Selatan.

Karena eskalasi konflik di Laut China Selatan, Angkatan Laut Jerman pada tahun 2016 untuk pertama kalinya berpartisipasi dalam latihan skala besar di Samudera Pasifik, yaitu the Rim of Pacific Exercise (RIMPAC). RIMPAC merupakan latihan tempur yang diorganisir oleh Angkatan Laut Amerika Serikat. Ada 25.000 tentara dari 26 negara yang ikut serta dari negara-negara anggota NATO dan aliansi Amerika dari Pantai Pasifik Amerika Latin hingga Asia Tenggara. Indonesia merupakan salah satu negara dari kawasan Asia Tenggara 
yang ikut bergabung dalam latihan gabungan RIMPAC untuk pertama kali (German foreign policy, 2016). Latihan yang diikuti Jerman dengan Indonesia tersebut memperlihatkan adanya kekhawatiran yang sama terkait eskalasi konflik di Laut China Selatan akibat dari peningkatan sikap China yang agresif.

Indonesia kemudian melalui Menko Maritim Luhut Pandjaitan dengan Jerman melalui Deputi Perdana Menteri Sigmar Gabriel menandatangani nota kesepahaman di bidang kemaritiman pada 31 Mei 2017 (Kementerian Riset dan Teknologi Indonesia, 2017). Kerjasama bilateral tersebut merupakan implementasi dari deklarasi bersama antara IndonesiaJerman dalam kerjasama komprehensif pada tahun 2012. Beberapa poin yang masuk ke dalam agenda kerjasama yaitu terkait strategis maritim, keamanan dan keselamatan laut, investasi infrastruktur maritim, investasi galangan kapal, kerjasama riset dan teknologi serta pelatihan. Selain penandatanganan nota kesepahaman kerjasama kemaritiman, adanya juga dialog dengan Deputi PM Jerman Sigmar Gabriel yang meliputi beberapa topik hangat yaitu geopolitik di kawasan, keamanan laut, kontrateririsme, dan kerjasama strategis Indonesia-Jerman (maritime.go.id, 2017).
Perjanjian kerjasama pertahanan dan transfer senjata oleh Jerman memperlihatkan adanya upaya Jerman dalam mengaplikasikan hegemonic power. Sikap China yang semakin agresif di Laut China Selatan dilihat sebagai ancaman yang dapat mengganggu stabilitas kawasan. Jerman memiliki kebijakan luar negeri yang berkomitmen pada kedamaian dan keamanan dunia. Salah satu bagian dari prinsip kebijakan kedamaian dan keamanan Jerman adalah dalam bidang pencegahan krisis, stabilisasi, pembangunan perdamaian pascakonflik dan bantuan kemanusiaan (Federal Foreign Office Germany, t.t).

Indonesia memiliki kemampuan untuk menjadi kekuatan utama (regional power) di Asia Tenggara dengan pertumbuhan ekonomi dan pengaruh politik yang signifikan di ASEAN. Tetapi, status Indonesia sebagai regional power belum tercermin dalam kekuatan militer Indonesia. Indonesia masih memiliki kesulitan dalam melakukan transformasi pertahanannya (Dzikri, 2016). Indonesia memiliki posisi geostrategis yang sangat penting baik dari sisi keamanan-pertahanan nasional, regional, bahkan global. Aspek kelautan nasional memiliki konsekuensi bagi signifikansi pengembangan pertahanan keamanan matra laut melalui dua pendekatan yaitu secara eksternal melalui peningkatan kerja sama angkatan laut 
baik bilateral maupun regional. Serta, secara internal dengan melakukan pembangunan kekuatan Angkatan Laut Indonesia (Perwita, 2004).

Mengingat pentingnya teritori perairan bagi negara-negara maritim, Indonesia harus mengorganisasi dan membangun kembali kekuatan maritim untuk memperkuat perekonomian dan ketahanan negara melalui penguatan maritim. Dalam era sekarang, ada banyak momen strategis yang dapat di manfaatkan oleh Indonesia dalam konteks penguatan urusan maritim, seperti masyarakat ekonomi ASEAN di Asia Tenggara, the Indian Ocean Rim Association for Regional Cooperation (IORARC), dan lainnya. (Yunus, Susilowati \& Sholeh, 2019).

Jerman berupaya untuk membentuk perilaku Indonesia, dari kerjasama pertahanan yang dilakukan dan pengiriman MBT Leopard, pengaruh Jerman dapat terlihat dengan adanya perluasan bidang kerjasama dengan Indonesia, yaitu salah satunya adalah dalam bidang maritim. Karena, kerjasama tersebut dapat mempengaruhi Indonesia dalam menyikapi permasalahan di Laut China Selatan. Indonesia juga memiliki persepsi ancaman yang sama dengan Jerman terkait sikap agresif China di Laut China Selatan.

Jerman mengaplikasikan hegemonic power untuk mendapatkan tujuan tertentu, yaitu kebebasan navigasi di Laut China Selatan, kerjasama dengan Indonesia sebagai negara dengan posisi dan pengaruh strategis di Asia Tenggara dapat memberikan hasil yang menguntungkan bagi Jerman. Kerjasama di bidang maritim tersebut juga dapat membantu Indonesia untuk menjaga stabilitas kawasan sebagai regional power dan sesuai dengan prinsip kebijakan kedamaian serta keamanan Jerman untuk menjaga stabilitas kawasan.

\section{KESIMPULAN}

Pengiriman Main Battle Tank (MBT) Leopard oleh Jerman ke Indonesia memperlihatkan bahwa meskipun Jerman memiliki regulasi kontrol ekspor yang berupa kode etik atas ekspor persenjataan, Jerman masih tetap setuju untuk mengirimkan tank tersebut ke Indonesia yang tercatat pernah melakukan pelanggaran HAM. Temuan dari penelitian ini adalah Jerman memiliki kepentingan untuk menggunakan kekuatan dan pengaruhnya melalui transfer MBT Leopard ke Indonesia yang diawali dari nota kesepahaman kerjasama di bidang pertahanan.

Ada tiga dimensi kekuatan dan pengaruh dari transfer senjata yang saling mempengaruhi, yaitu bargaining power, structural power, dan begemonic power. Dalam aplikasi bargaining power yang memiliki efek langsung atau 
jangka pendek, Jerman memastikan Indonesia tidak akan menggunakan MBT Leopard yang dikirimkan untuk melakukan pelanggaran HAM yang diperkuat melalui pernyataan terkait transparansi penggunaan senjata oleh Presiden Indonesia saat itu, yaitu Susilo Bambang Yudhoyono. Serta, Jerman setuju untuk melakukan Transfer of Technology (ToT) melalui pengiriman MBT Leopard.

Lalu, untuk aplikasi structural power, Jerman membatasi respon pada ancaman yang dihadapi oleh Indonesia, yaitu terkait ancaman kedaulatan. Indonesia membutuhkan tank tempur utama untuk melindungi kedaulatan negara. Hal itu muncul karena negara-negara di Asia Tenggara telah memiliki tank tempur utama. Jerman juga merubah pilihan Indonesia sehingga Indonesia pada akhirnya tetap memilih Jerman untuk membeli MBT Leopard. Hal tersebut terlihat ketika Jerman setuju untuk mengirimkan MBT Leopard ke Indonesia, setelah sebelumnya pengiriman tank tersebut ditolak oleh Belanda. Kemudian, Jerman juga memodifikasi MBT Leopard sesuai dengan kondisi cuaca di Indonesia. MBT Leopard memberikan daya gentar yang dibutuhkan oleh Indonesia yang sebelumnya tidak memiliki Main Battle Tank dan hanya memiliki small serta medium battle tank. Selain itu, Jerman melalui perusahaan
Rheinmetall menjadikan Indonesia sebagai pusat manufaktur Rheinmetall di Asia-Pasifik melalui penandatanganan nota kesepahaman pada tahun 2014.

Dalam aplikasi hegemonic power, kerjasama pertahanan yang dilakukan dengan Indonesia dapat meluas ke sektor lain. Kerjasama pertahanan tersebut dapat mendukung kepentingan Jerman di Laut China Selatan. Jerman berupaya untuk membentuk perilaku Indonesia melalui kerjasama di bidang maritim untuk mendapatkan tujuan tertentu, yaitu kebebasan navigasi di Laut China Selatan. Karena Indonesia merupakan negara yang memiliki pengaruh besar di kawasan Asia Tenggara, kerjasama yang dilakukan dengan Indonesia dapat memberikan keuntungan bagi Jerman.

\section{REFERENSI}

Albrecht, U. (1986) “The Federal Republic of Germany and Italy: New Strategies of Mid-Sized Weapons Exporters?". Journal of International Affairs, 40(1), pp. 129-142. From: www.jstor.org/stable/24356495.

Bauer S. (2003) "The EU Code of Conduct on Arms Exports - Enhancing the Accountability of Arms Export Policies?”, European Security, 12:3-4, 129-147.

Beeck, C. (2008) "Germany: From Surplus Exports to Destruction". Contemporary Security Policy, 29:1, 53-77, DOI: 10.1080/13523260801994550. 
Béraud-Sudreau, L. (2019) "Building Franco-German Consensus on Arms Exports", Survival, 61:4, 79-98, DOI: 10.1080/00396338.2019.1637124.

Buzan, B., \& O. Waever. (2003) Regions and Powers: The Structure of International Security. United Kingdom: Cambridge University Press.

Deutsche Welle. (2013) Jerman Ijinkan Penjualan Tank ke Indonesia (Online). Available at: https://www.dw.com/id/jermanijinkan-penjualan-tank-keindonesia/a-16799015 (Diakses:: 15 April 2020).

Dewan Perwakilan Rakyat Republik Indonesia. (2012) Laporan Kunjungan Kerja Komisi I DPR RI ke Negara Republik. Federasi Jerman dalam reses masa persidangan III Tabun Sidang 2011-2012 (Online). Available at: https://www.dpr.go.id/dokakd/doku men/K1_kunjungan_Laporan_Kunju ngan_Kerja_Komisi_I_DPR_RI_ke_J erman,_22_-_26_April_2012.pdf (Diakses: at: 23 June 2021).

Dzikri, I. (2016) "Negara dan Kapasitas Adopsi Inovasi: Studi Kasus Transformasi Pertahanan Indonesia Periode 1998-2014", Global: Jurnal Politik Internasional (18)2, 131-151 DOI: 10.7454/global.v18i2.305.

Epkenhans, M. (2003) “Military Industrial Relations in Imperial Germany, 18701914". War in History, 10(1), 1-26. https://doi.org/10.1191/0968344503 wh270oa.

Erickson, J. L. (2013) "Market imperative meets normative power: Human rights and European arms transfer policy", European Journal of International Relations, 19(2), 209-234. https://doi.org/10.1177/1354066111 415883.

Federal Foreign Office Germany. (t.t) Germany's foreign and European policy principles (Online). Available at: https://www.auswaertigesamt.de/en/aussenpolitik/themen/pol icy-principles /229790 (Diakses:: 27 April 2020).

German Foreign Policy. (2016) W ar Exercises in the Pacific (Online). Available at: https://www.german-foreignpolicy.com/en/news/detail/7041/ (Diakses:: 27 April 2020).

Hardy, J. (2013) Rheinmetall confirms Indonesian Leopard 2 contract (Online). Available at: https://www.janes.com/article/29983 /rheinmetall-confirms-indonesianleopard-2-contract (Diakses:: 17 April 2020).

Hayton (2019) "How Europe can make a difference in the South China Sea", Berlin Policy Journal (Online). Available at:

https://berlinpolicyjournal.com/howeurope-can-make-a-difference-in-thesouth-china-sea/ (Diakses:: 27 April 2020).

Heiduk, F. (2017) 'An Arms Race in Southeast Asia?', SWP Research Paper. (Online) Available at: https://www.swpberlin.org/fileadmin/contents/produc ts/research_papers/2017RP10_hdk.p df (Diakses: at: 12 April 2020).

Kemaritiman dan Investasi. (2017) Menko Lubut Teken MoU Kerjasama Bilateral Maritim Dengan Jerman (Online). Available at: https://maritim.go.id/menko-luhutteken-mou-kerjasama-bilateralmaritim-dengan-jerman/ (Diakses: at: 29 April 2020).

Kementerian Luar Negeri Indonesia (t.t) Sekilas Hubungan Bilateral Indonesia dan Jerman (Online). Available at: https://kemlu.go.id/berlin/id/read/s ekilas-hubungan-bilateral-indonesiadan-jerman/1287/etc-menu (Diakses: at: 2 April 2020). 
Kementerian Pertahanan Republik Indonesia. (2012) Kemban-Rheinmettal Tandatangani Nota Kesepahaman Pengadaan Leopard (Online). Available at:

https://www.kemhan.go.id/baranaha n/2012/11/08/kemhan-rheinmettaltandatangani-nota-kesepahamanpengadaan-leopard.html (Diakses: at: 2 April 2020).

Kementerian Riset dan Teknologi. (2017) Indonesia dan Jerman sepakati kerja sama di bidang maritim (Online). Available at: https:// risbang.ristekbrin.go.id/publi kasi/berita-media/indonesia-danjerman-sepakati-kerja-sama-di-bidangmaritim/ (Diakses: at: 28 April 2020).

Kenny, B., \& Stessen, L. (1996) "UK and German defence industry change: Some perspectives on strategic marketing", Journal of Marketing Management, 12(6), 561-579. doi:10.1080/0267257x.1996.9964435.

Kinsella, D. (1998) “Arms Transfer Dependence and Foreign Policy Conflict", Journal of Peace Research, 35(1), 7-

23. doi: $10.1177 / 002234339803500100$ 2.

Krause K. (1991) "Military Statecraft: Power and Influence in Soviet and American Arms Transfer Relationship", International Studies Quarterly, (35)3, 313-336.

Krause, K. (1992) Introduction. In Arms and the State: Patterns of Military Production and Trade (Cambridge Studies in International Relations, pp. 1-11). Cambridge: Cambridge University Press. doi:10.1017/CBO9780511521744.001

Lock, P. \& Voß, W. (1994) “The German arms industry in a European context: A study in successful downsizing", Defence and Peace Economics, 5 (4), 341 348, DOI: 10.1080/10430719408404804.
Neuman, S.G. (2009) "Power, Influence, and Hierarchy: Defense Industries in a Unipolar World", Defence and Peace Economics, 2010 21(1), 105-134. doi: 10.1080/10242690903105398.

Patnistik E. (2012) Dilema Leopard Belanda: HAM atau Dagang (Online). Available at: https:// nasional.kompas.com/read/2 012/02/07/07505617/dilema.leopard. belanda.ham.atau.dagang (Diakses: 25 April 2020).

Perwita, A. (2004) "Sekuritisasi Isu Maritim: Koordinasi Nasional dan Kerangka Kerja Sama Maritim Regional di Asia Tenggara”, Global: Jurnal Politike Internasional 7(1), pp. 35-47.

Platte, H., \& Leuffen, D. (2016) “German Arms Exports: Between Normative Aspirations and Political Reality", German Politics, 25(4), 561-580. doi:10.1080/09644008.2016.1184651.

Prajuli, W. (2013) “China-Threat Perceptions in Southeast Asia: Problem of Bilateral Interactions", Global: Jurnal Politik Internasional, 15(1) pp. 1-14.

Pratomo, Y. (2012) Tank Leopard tidak untuk tembaki rakyat sendiri (Online).

Available at: https://www.merdeka.com/peristiwa /sby-tank-leopard-tidak-untuktembaki-rakyat-sendiri.html (Diakses: at: 5 April 2020).

PT. Pindad (2014) PT. Pindad (Persero) gandeng Rheinmetall Denel Munition Proprietary Limited (RDM) untuk menjadi produsen (Online). Available at: https://www.pindad.com/pindadrdm (Diakses: at: 26 April 2020).

Rachmat, A.N. (2014) “Tantangan dan Peluang Perkembangan Teknologi Pertahanan Global Bagi Pembangunan Kekuatan Pertahanan Indonesia", Jurnal Transformasi Global 1(2). pp. 199-212. https://transformasiglobal.ub.ac.id/in 
dex.php/trans/article/viewFile/19/1 8.

Rohde, J. \& Schmidt, P. (1995) "German armaments policy: Its consequences for the armaments industry", Defense Analysis, 11(3), 269-277, DOI: 10.1080/07430179508405666.

Sihite, E. (2014) Menhan: Indonesia juga perlu punya Leopard (Online). Available at: https://investor.id/archive/menhanindonesia-juga-perlu-punya-leopard (Diakses: at: 28 April 2020).

Sislin, J. (1994) “Arms as Influence: The Determinants of Successful Influence", Journal of Conflict Resolution 38(4), pp. 665-689.

Sitanggang, H. (2014) Militer Indonesia Butuh MBT Leopard (Online). Available at: https:// nasional.republika.co.id/berit a/nasional/umum/14/06/27/n7t207militer-indonesia-butuh-mbt-leopard (Diakses: at: 23 June 2021).

Tempo (2012) Tank Leopard Tiba di Jakarta Hari Ini (Online). Available at: https:// nasional.tempo.co/read/4396 18/tank-leopard-tiba-di-jakarta-hariini/ full\&view $=$ ok (Diakses: at: 5 April 2020).

Tempo. (2014) Mengenal Tank Leopard, Bintang Baru HUT TNI (Online) Available at: https://nasional.tempo.co/read/6127 54/mengenal-tank-leopard-bintangbaru-hut-tni/ full\&view $=$ ok (Diakses: at: 26 April 2020).

The Guardian. (2015) Angela Merkel worried about 'serious conflict' in South China Sea (Online). Available at: https://www.theguardian.com/world /2015/oct/29/angela-merkel-seriousconflict-south-china-sea (Diakses: at: 29 April 2020).
Thurner, P., et. al. (2019) "Network Interdependencies and the Evolution of the International Arms Trade", Journal of Conflict Resolution, 63(7), 1736-1764. doi: 10.1177/0022002718801965.

Waluyo. (2012) Indonesia-Jerman Sepakati Deklarasi Jakarta (Online). Available at: https://www.voaindonesia.com/a/in donesia-jerman-sepakati-deklarasijakarta/1382416.html (Diakses: at: 12 April 2020).

Wezeman, S.T. (2019) Arms Flows to South East Asia (Online). Available at: https://www.sipri.org/sites/default/f iles/201912/1912_arms_flows_to_south_east_ asia_wezeman.pdf (Diakses: at: 12 April 2020).

Wulf, H. (1988) "The West German Arms Industry and Arms Exports", Alternatives: Global, Local, Political, 13(3), 319-335. doi:10.1177/030437548801300302.

Yunus, N.R., Susilowati, I., \& Sholeh, M. (2019) "Global Maritime Fulcrum Optimiztion In Maintaining Indonesian Maritime Sovereignty", Mandala Jurnal Ilmu Hubungan Internasional, 2(2), 169-182. 